Article

\title{
Investigation of Element Effect on High-Temperature Oxidation of HVOF NiCoCrAlX Coatings
}

\author{
Pimin Zhang ${ }^{1, *(\mathbb{D},}$, Ru Lin Peng ${ }^{1}$, Xin-Hai Li ${ }^{2}$ and Sten Johansson ${ }^{1}$ \\ 1 Department of Management and Engineering, Linköping University, 58183 Linköping, Sweden; \\ ru.peng@liu.se (R.L.P.); sten.johansson@liu.se (S.J.) \\ 2 Siemens Industrial Turbomachinery AB, 61283 Finspång, Sweden; xin-hai.li@siemens.com \\ * Correspondence: pimin.zhang@liu.se
}

Received: 14 March 2018; Accepted: 1 April 2018; Published: 3 April 2018

check for updates

\begin{abstract}
MCrAlX (M: Ni or Co or both, X: minor elements) coatings have been used widely to protect hot components in gas turbines against oxidation and heat corrosion at high temperatures. Understanding the influence of the $X$-elements on oxidation behavior is important in the design of durable MCrAlX coatings. In this study, NiCoCrAlX coatings doped with $\mathrm{Y}+\mathrm{Ru}$ and $\mathrm{Ce}$, respectively, were deposited on an Inconel-792 substrate using high velocity oxygen fuel (HVOF). The samples were subjected to isothermal oxidation tests in laboratory air at 900,1000 , and $1100{ }^{\circ} \mathrm{C}$ and a cyclic oxidation test between 100 and $1100{ }^{\circ} \mathrm{C}$ with a 1-h dwell time at $1100^{\circ} \mathrm{C}$. It was observed that the coating with Ce showed a much higher oxidation rate than the coating with $\mathrm{Y}+\mathrm{Ru}$ under both isothermal and cyclic oxidation tests. In addition, the $\mathrm{Y}+\mathrm{Ru}$-doped coating showed significantly lower $\beta$ phase depletion due to interdiffusion between the coating and the substrate, resulting from the addition of Ru. Simulation results using a moving phase boundary model and an established oxidation-diffusion model showed that Ru stabilized $\beta$ grains, which reduced $\beta$-depletion of the coating due to substrate interdiffusion. This paper, combining experiment and simulation results, presents a comprehensive study of the influence of $\mathrm{Ce}$ and $\mathrm{Ru}$ on oxidation behavior, including an investigation of the microstructure evolution in the coating surface and the coating-substrate interface influenced by oxidation time.
\end{abstract}

Keywords: MCrAlX coatings; Ruthenium; Cerium; oxidation; simulation

\section{Introduction}

MCrAlX coatings ( $\mathrm{M}$ for $\mathrm{Ni}$ and/or $\mathrm{Co}, \mathrm{X}$ for minor elements) are widely used to protect superalloys against high-temperature oxidation and heat corrosion in gas turbine engines, either as overlays or as bond coats for TBCs (Thermal barrier coatings) [1-3]. The protection offered by MCrAlX coatings against high-temperature oxidation relies on the performance of a thermally grown oxide (TGO) scale formed at the coating-gas interface [4,5]. A continuous and dense $\alpha-\mathrm{Al}_{2} \mathrm{O}_{3}$ of hexagonal, close-packed structures is desired for the scale's resistance against the diffusion of oxygen ions, as well as high thermal and chemical stabilities. The growth of the alumina scale at the coating surface and substrate interdiffusion depletes the Al-rich $\beta$ phase in $\mathrm{MCrAlX}$ coatings, which serves as an $\mathrm{Al}$ reservoir during oxidation. By modifying these two processes, the $\beta$ phase depletion rate can be reduced; therefore, improved coating oxidation performance can be achieved by doping elements, such as Y [6,7], Hf [8,9], Ta [10], Re [11], and so on.

Compared with isothermal oxidation, cyclic oxidation induces thermal stress on TGO, resulting in TGO spallation [12]. The addition of various reactive elements ( $\mathrm{Y}, \mathrm{Hf}$, or $\mathrm{Ce}$ ) to alloys and coatings can remarkably improve TGO spallation resistance during cyclic oxidation by creating an anchor effect [13]. Among all of the reactive elements, Cerium's (Ce) effect on improving oxidation performance has 
drawn attention in recent years. It has been reported that the adherence of the oxide film formed on $\mathrm{Ni}-20 \mathrm{Cr}$ alloys is improved by small additions of $\mathrm{Ce}$ and $\mathrm{Si}$ near the formation of root-shape protrusions, which inhibits the propagation of cracks at the TGO and increases the spallation resistance [14,15]. On the other hand, substrate interdiffusion between the coating and the substrate also depletes the $\beta$ phase, which is greatly dependent on coating composition, substrate composition, and oxidation temperature [16-18]. The reduction of inwards diffusion of the $\mathrm{Al}$ from the coating to the substrate may significantly extend the lifetime of MCrAlX coatings. It is has been reported that by depositing a Ru layer between the coating and the substrate, it effectively slows down the inward diffusion of the $\mathrm{Al}$ by the formation of a ( $\mathrm{Ru}, \mathrm{Ni}) \mathrm{Al}$ layer as diffusion barrier [19]. Moreover, the addition of $\mathrm{Ru}$ in Ni-based superalloys is also beneficial because it decreases the precipitation and growth rate of topologically close-packed (TCP) phases, which prevent the degradation of mechanical properties [20].

Overall oxidation resistance is closely related to the coating composition, and a large number of publications have been dedicated to studying the effects of minor additions of alloying elements to the coating composition $[10,11,18,21-23]$. However, no effort has been made to compare the abilities of Ce and other reactive elements (REs), such as $Y$, to improve cyclic oxidation resistance, and the effect of Ru-doping in the MCrAlX coating on substrate interdiffusion has rarely been discussed. This work covers two parts: (1) a comparative study of high velocity oxygen fuel (HVOF) sprayed coatings using isothermal oxidation and cyclic oxidation tests to analyze the effect of $\mathrm{Ce}$ on cyclic oxidation resistance; and (2) a study of the effect of Ru on the stability of the $\beta$ phase and the $\mathrm{Al}$ interdiffusion using both short-range and long-range models to simulate the phase evolution and interdiffusion in the coating of superalloy systems [23-25]. This paper aims to better understand the effects of Ru and Ce on the behavior of MCrAlX coatings during high-temperature oxidation.

\section{Materials and Experiment}

In this study, two NiCoCrAlX powders were tailor-made by the Beijing General Research Institute of Mining (Beijing, China) with a size range of $<37 \mu \mathrm{m}$ for $\mathrm{C} 1$ and $30-53 \mu \mathrm{m}$ for C2. NiCoCrAlX coatings were deposited on an Inconel 792 substrate (composition by wt \%: $12.5 \mathrm{Cr}, 9 \mathrm{Co}, 4.2 \mathrm{~W}$, 4.2 Ta, $4 \mathrm{Ti}, 3.4 \mathrm{Al}, 1.9 \mathrm{Mo}, 0.08 \mathrm{C}, 0.03 \mathrm{Zr}+\mathrm{B}$, balanced by Ni), using the JP5000 HVOF spray system (GTV-MF-P-HVOF-K-ARC, GTV Verschleiss-Schutz GmbH, Luckenbach, Germany). The NiCoCrAlX coating thicknesses were measured around $200 \mu \mathrm{m}$ using Image software (version 1.51) with the coating roughness in the range between 6 and $6.5 \mu \mathrm{m}$. Prior to coating deposition, the substrate surfaces were grit blasted. After the deposition, the specimens were subjected to a heat treatment, including solution annealing at $1120^{\circ} \mathrm{C}$ for $2 \mathrm{~h}$ in a vacuum, followed by aging treatment at $845^{\circ} \mathrm{C}$ for $24 \mathrm{~h}$ in air and air cooling to room temperature. Such a heat treatment, which is intended to strengthen the IN-792 substrate [26], also increases the bond strength between the coating and the substrate [27]. The chemical composition of the heat-treated MCrAlX coatings was measured on the average $20 \mu \mathrm{m} \times 25 \mu \mathrm{m}$ cross-section area by an energy dispersive spectroscope (EDS, X-Max, Oxford Instruments, Oxford, UK) and a wavelength dispersive spectroscope (WDS, INCA wave, Oxford Instruments, Oxford, UK), as listed in Table 1.

Table 1. Chemical composition of heat-treated Ni27Co15Cr12.5AlX coatings (in wt \%).

\begin{tabular}{ccccc}
\hline MCrAlX & $\mathbf{X}=\mathbf{R u}$ & $\mathbf{X}=\mathbf{C e}$ & $\mathbf{X}=\mathbf{Y}$ & $\mathbf{X}=$ Others \\
\hline C1 & 3.3 & - & 0.3 & $0.3 \mathrm{Si},(\mathrm{Mo}, \mathrm{Ta})<0.6$ \\
C2 & - & 0.2 & - & \\
\hline
\end{tabular}

Long-time isothermal oxidation tests were performed on the coated specimens at 900 and $1000{ }^{\circ} \mathrm{C}$ - which is close to the service temperature of the MCrAlX coating of a gas turbine component- to simulate oxidation behavior. Cyclic oxidation tests were conducted in laboratory air at $1100{ }^{\circ} \mathrm{C}$ to compare with the isothermal oxidation tests and to study the coating's cyclic oxidation resistance (see Table 2 for details). One cycle of the cyclic oxidation consisted of heating at $1100{ }^{\circ} \mathrm{C}$ 
for $1 \mathrm{~h}$ and forced-air cooling to $100{ }^{\circ} \mathrm{C}$ in $10 \mathrm{~min}$. After oxidation, the oxidized samples were sectioned, mounted in epoxy, and polished. The surface and the cross-sections of the specimens were examined using a Hitachi SU70 FEG scanning electron microscope (SEM, Hitachi, Tokyo, Japan) for microstructure observation and chemical composition measurement. To better describe the microstructure development, the coating was separated into several zones, including: outer $\beta$ phase depletion zone (OBDZ), $\beta$ phase left zone (BLZ), and inner $\beta$ phase depletion zone (IBDZ), as illustrated in Figure 1. The evolution of different areas were quantified by image analysis software.

Table 2. Conditions of oxidation test.

\begin{tabular}{cc}
\hline Condition & Time/Cycle \\
\hline Isothermal oxidation- $900{ }^{\circ} \mathrm{C}$ & $500,1500,5000 \mathrm{~h}$ \\
Isothermal oxidation- $1000^{\circ} \mathrm{C}$ & $500,1500,5000 \mathrm{~h}$ \\
Isothermal oxidation- $-1100^{\circ} \mathrm{C}$ & $50,300,500,800 \mathrm{~h}$ \\
Cyclic oxidation & $50,300,500,800$ cycles \\
\hline
\end{tabular}
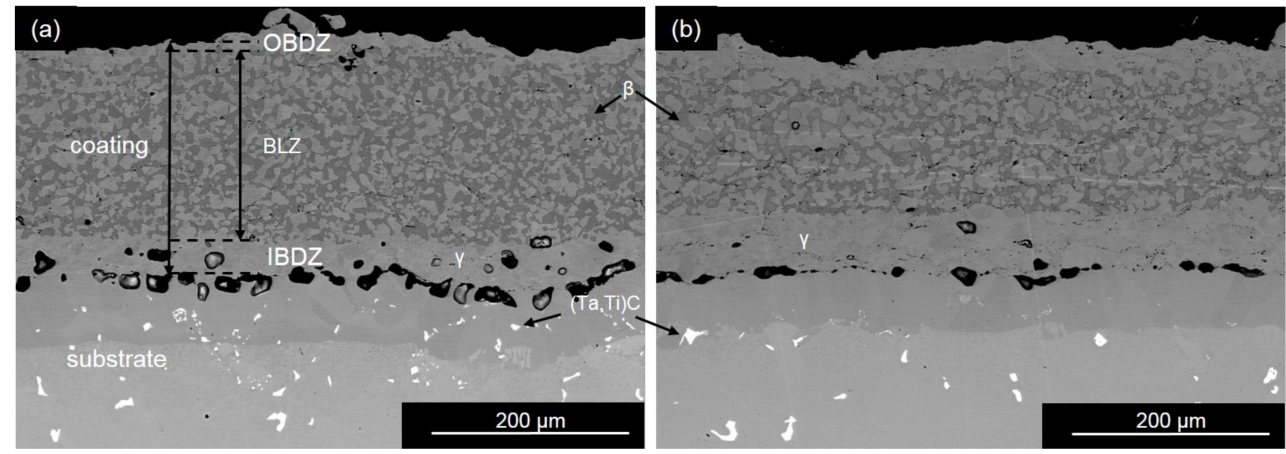

Figure 1. BSE (backscattered-electron) image showing microstructure of the $\mathrm{C} 1$ (a) and C2 (b) coating of isothermal $1100{ }^{\circ} \mathrm{C}$ specimen after $800 \mathrm{~h}$ oxidation.

\section{Simulation}

To have a better understanding of the mechanism behind the effect of $\mathrm{Ru}$ on the $\mathrm{Al}$ diffusion behavior, the experimental work was supplemented with a computational simulation, using a Thermo-Calc software (version 2017b) package with the advanced Ni-base thermodynamic database TCNI8 [28] and corresponding mobility database MONI4 [29]. Firstly, to investigate the influence of Ru addition in MCrAlX coatings, Ru and Al solubility in the constituent $\beta$ and $\gamma$ phases and the corresponding phase equilibrium were calculated using Thermo-Calc. Secondly, the Ru effect on the Al diffusion between the localized $\beta$ and $\gamma$ grains was investigated by a short-range diffusion calculation using the moving phase boundary model in DICTRA (version 2017b) [30]. Finally, a long-range interdiffusion simulation between the coating and the substrate using an established model $[17,23,24]$ based on DICTRA was performed to demonstrate the aforementioned Ru effect on the Al diffusion. The models are introduced below in Sections 3.1 and 3.2, respectively.

\subsection{Short-Range Diffusion}

To study the Ru effect on the Al diffusion between the $\beta$ and $\gamma$ phase, a 1D moving phase boundary model, which has been incorporated in DICTRA software [30], was adapted to simulate the short-range diffusion behavior. The model is based on the diffusion-controlled growth under local equilibrium conditions as suggested by Larsson and Reed [31]. A more intimate and comprehensive description can be found in [32]. The assumption for this model includes: (1) planar geometry corresponding to an infinitely wide plate of a certain thickness; (2) a sharp interface with local equilibrium; (3) diffusion controlling the movement of the phase boundary; and (4) zero-flux at the boundary. The utilization of such a model to simulate diffusion in MCrAlX coatings can be useful to investigate: (1) the movement 
of the interfacial $\beta / \gamma$ phase boundary and (2) the local diffusion behavior of the Al between the $\beta$ and $\gamma$ phase at short time because since no flux is introduced into the system. The model includes the diffusion process through the interface between the two regions (the $\gamma$ phase region on the left side and the $\beta$ phase region on the right side) and phase equilibrium calculation for each region. The region lengths, $5.5 \mu \mathrm{m}$ for $\gamma$ and $4.5 \mu \mathrm{m}$ for $\beta$, were measured from the average grain size on the heat-treated samples. A double grit structure was set with a set of non-linear nodes for each region with a geometry factor of 0.9 (linear grid when geometry factor is 1), which gives a distribution of nodes: denser closer to the interface and thinner near the outer region boundaries. The composition of the phases was stored in each node. The composition profile in the $\gamma$ and $\beta$ regions was linear, which was taken either from EDS measurement of as-received samples or from equilibrium calculation of corresponding coating composition by Thermo-Calc.

\subsection{Long-Range Diffusion}

A brief description of the oxidation-diffusion model for the simulation of long-range diffusion is given as follows; a more detailed description can be found in $[11,15,19]$. The substrate and coating compositions were represented in 1D by a set of non-linearly distributed nodes (dense near the interface, coarse in the substrate), in which the local composition is stored. In this paper, the nominal compositions in Table 1 were used as input data. The simulation of oxidation and diffusion followed an iterative process in which each iteration included: Step 1, Al removal from the coating surface to simulate the $\mathrm{Al}$ depletion at coating surface due to the formation of alumina using a MATLAB script (version 2017b); and Step 2, phase equilibrium calculation and substrate interdiffusion simulation using DICTRA software. The obtained compositions were then used as input data for the next loop.

\section{Results and Discussion}

\subsection{Experimental Results Analysis}

\subsubsection{Heat-Treated Coating}

The cross-section of heat-treated coatings and EDS mapping results are shown in Figures 2 and 3 for the $\mathrm{C} 1$ and $\mathrm{C} 2$ coatings, respectively. A characteristic splat-on-splat structure can be seen with pores and cracks marking the splat's boundaries. After the solution and aging heat treatment, a typical $\beta+\gamma$ microstructure formed in the coatings ( $\beta$ phase in dark grey). The EDS mapping results are shown in Figure $2 b$, Ru has a similar pattern as $\mathrm{Al}$ indicating that Ru has a higher solubility in $\beta$ phase than in $\gamma$ phase, which is also confirmed by EDS point analysis showing a $4.8 \mathrm{wt} \%$ for Ru in $\beta$ phase, compared with $1.1 \mathrm{wt} \%$ for Ru in $\gamma$ phase. $\mathrm{Y}$ and Ce were mainly segregated to the splat's boundary according to the EDS mapping (Figures $2 b$ and $3 b$ ) due to their affinity for oxygen.
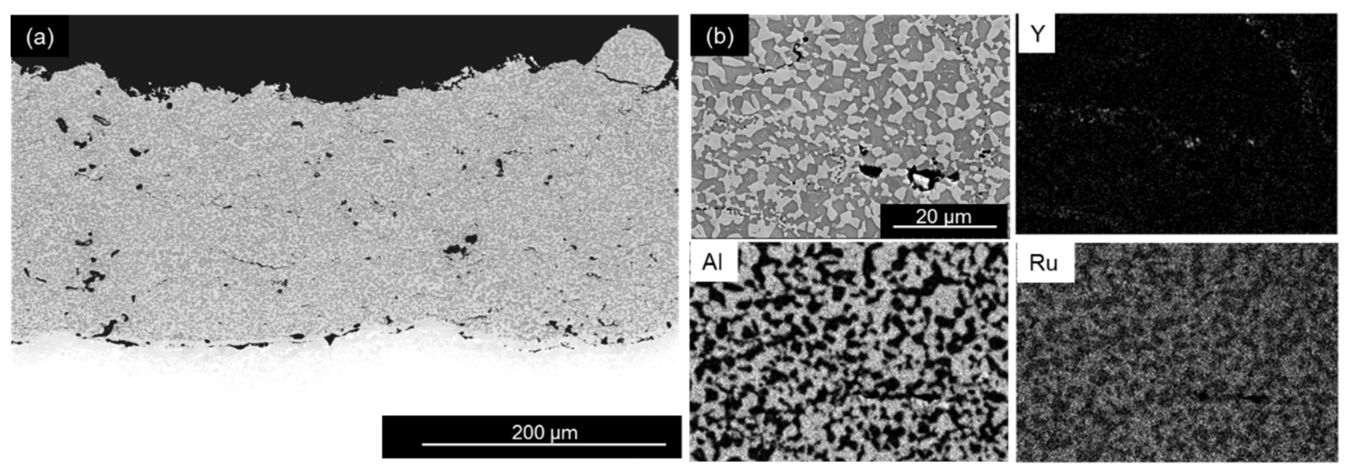

Figure 2. BSE image showing the cross-section of heat-treated coating of $\mathrm{C} 1$ (a) and energy dispersive spectroscope (EDS) mapping of $\mathrm{Y}, \mathrm{Al}$, and $\mathrm{Ru}$ in the heat-treated coating (b). 

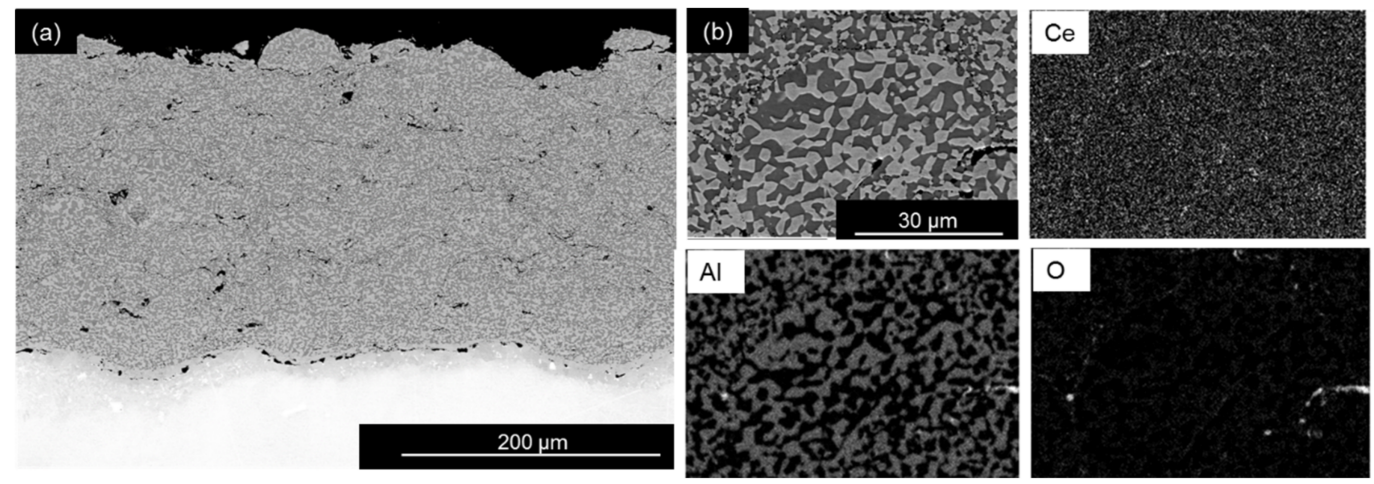

Figure 3. BSE image showing the cross-section of heat-treated coating of C2 (a) and EDS mapping of $\mathrm{Ce}, \mathrm{Al}$, and $\mathrm{O}$ in the heat-treated coating $(\mathbf{b})$.

\subsubsection{Thermally Grown Oxide Microstructure}

The formation and growth of TGO play an important role in its subsequent thickening [33]; therefore, the oxidation behavior of coatings can be evaluated by studying the TGO growth behavior. Figures 4-7 show the cross-sectional microstructure of the alumina scale formed on the coating surface at different oxidation temperatures. In general, a two-layer structure of alumina scale was observed, containing an outer porous layer and an inner dense layer. In addition, spinel could also be found covering the alumina scale, as shown in Figures 5-7. However, the microstructure of the alumina scale is greatly dependent on the oxidation temperature. In Figure $4 \mathrm{a}, \mathrm{c}$, for $900{ }^{\circ} \mathrm{C}$ oxidation, a thick outer layer consisted of blade-like alumina and a thin dense inner alumina layer was observed with their boundaries marked by a dashed line. The formation of the blade-like $\mathrm{Al}_{2} \mathrm{O}_{3}$ resulted from the fast-outward growth of $\theta-\mathrm{Al}_{2} \mathrm{O}_{3}$ for a short exposure time at a relatively low temperature $\left(900{ }^{\circ} \mathrm{C}\right)$, which later transformed into $\alpha-\mathrm{Al}_{2} \mathrm{O}_{3}$, as suggested by Liu et al. [34]. Because the growth rate of $\theta-\mathrm{Al}_{2} \mathrm{O}_{3}$ is 10 times faster than $\alpha-\mathrm{Al}_{2} \mathrm{O}_{3}[35,36]$, the inner alumina layer grows inward much slower than the outward growth of $\theta-\mathrm{Al}_{2} \mathrm{O}_{3}$. Eventually, a two-layer structure of alumina scale, consisting of a thick porous outer layer transformed from fast-grown $\theta-\mathrm{Al}_{2} \mathrm{O}_{3}$ and an inner slow-grown $\alpha-\mathrm{Al}_{2} \mathrm{O}_{3}$, was observed. The formation of pores in the outer alumina layer gives evidence for the $\theta$-to- $\alpha \mathrm{Al}_{2} \mathrm{O}_{3}$ transformation due to the volume reduction, which is then incorporated in outer layer upon further alumina scale development $[37,38]$. After the full $\theta$-to- $\alpha \mathrm{Al}_{2} \mathrm{O}_{3}$ transformation, the inward diffusion of oxygen through the oxide scales dominates due to the slower $\mathrm{Al}$ outward diffusion through the oxides scale in a much more closely packed structure of $\alpha-\mathrm{Al}_{2} \mathrm{O}_{3}$, rather than transient $\mathrm{Al}_{2} \mathrm{O}_{3}[35,36]$. Therefore, the main alumina growth mechanism shifted from the outward grown outer layer to the inward growth of inner alumina layer after $5000 \mathrm{~h}$ oxidation, as evidenced by the similar outer layer thickness and the obvious thickening of inner layer in Figure 4. The outer layer of two coatings show similar morphology and thickness, indicating similar outward growth behavior. The inner alumina layer of the $\mathrm{C} 1$ coating, incorporated with Y-rich oxides (Figure $4 \mathrm{~b}$ ), is thicker than that of the $\mathrm{C} 2$ coating for $5000 \mathrm{~h}$ oxidation. This is because the Y-rich oxide in the alumina provides a fast diffusion path for the $\mathrm{Al}$, which leads to a faster inward growth rate of the alumina in the $\mathrm{C} 1$ coating $[22,33,39-41]$. However, no such effect could be observed on the Ce-doped C2 coating, indicating that the $0.2 \mathrm{wt} \%$ Ce addition in the MCrAlX coating does not modify the Al diffusion in the alumina scale. 

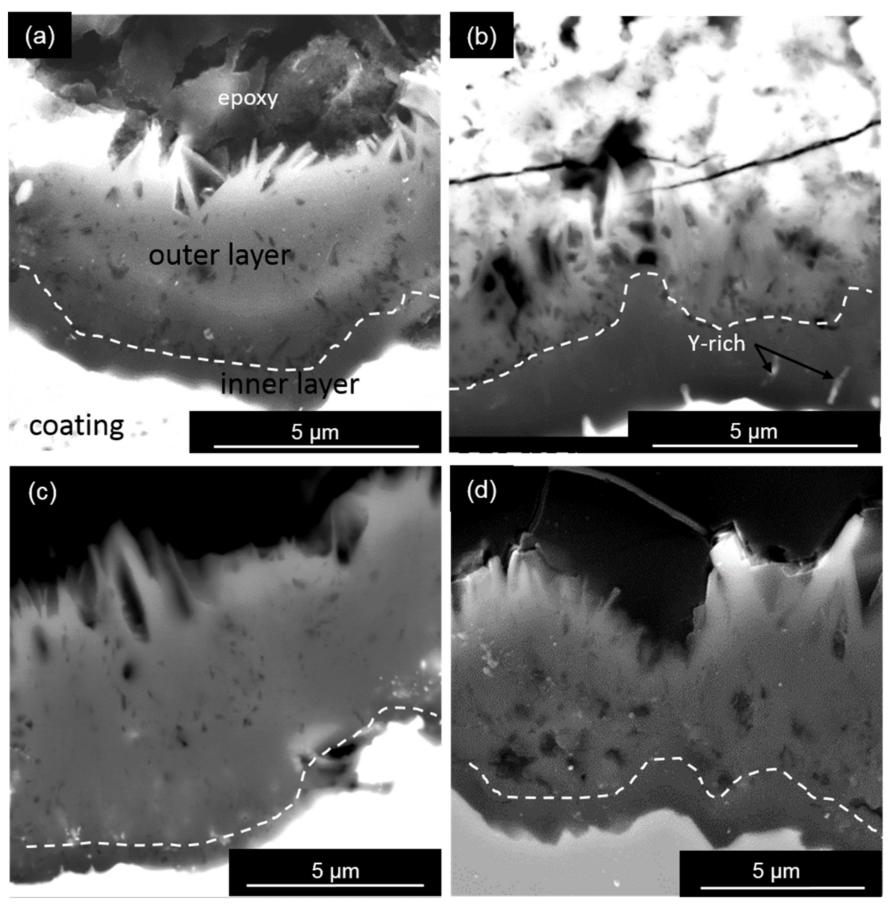

Figure 4. Cross-section of the thermally grown oxide (TGO) after isothermal oxidation at $900{ }^{\circ} \mathrm{C}$, $\mathrm{Y}+\mathrm{Ru}$-doped C1 coating for $500 \mathrm{~h} \mathrm{(a)} \mathrm{and} 5000 \mathrm{~h} \mathrm{(b)}$; Ce-doped C2 coating for $500 \mathrm{~h} \mathrm{(c)} \mathrm{and} 5000 \mathrm{~h}$ (d). White dashed lines marked the outer/inner $\mathrm{Al}_{2} \mathrm{O}_{3}$ layer boundary. (Note that the images are in different magnifications, the white contrast in (b) is due to charging problem).

Figure 5 shows the cross-section of the TGO formed on the $\mathrm{C} 1$ and $\mathrm{C} 2$ coatings after isothermal oxidation at $1000{ }^{\circ} \mathrm{C}$ for different oxidation times, showing that the TGO consisted of spinel, an outer alumina layer, and an inner alumina layer. A thin outer layer and a columnar inner layer alumina scale could be observed on the $\mathrm{C} 1$ coating. However, the alumina scale formed on the $\mathrm{C} 2$ coating consisted of a thick porous outer layer and an equiaxed inner layer. Upon further oxidation to $5000 \mathrm{~h}$, the thickening of inner layer in the $\mathrm{C} 1$ coating dominates the overall growth of the alumina scale after $50 \mathrm{~h}$ oxidation, as indicated by the relatively similar outer layer thickness. Figure 6 shows EDS mapping of the alumina scale formed on the $\mathrm{C} 1$ coating after $5000 \mathrm{~h}$ oxidation at $1000{ }^{\circ} \mathrm{C}$. Y-rich oxides incorporated in the alumina scale can be readily observed. No Ru could be identified in the TGO of the $\mathrm{C} 1$ coating by EDS, and no Ce could be identified in the TGO of the C 2 coating by EDS. The formation of the columnar structure of the inner alumina layer in the $\mathrm{C} 1$ coating resulted from the segregation of the Y-rich oxide at the alumina grain boundaries. The segregation of the Y-rich oxide accelerates the $\mathrm{Al}$ grain boundary diffusion, which aids in the formation of the columnar structure [42]. No such influence from the Ce addition in the $\mathrm{C} 2$ coating can be observed. In addition, the much thicker porous outer layer on the $\mathrm{C} 2$ coating compared to that of the $\mathrm{C} 1$ coating indicates that the addition of $\mathrm{Y}$ in MCrAlX coatings suppresses the growth of $\theta-\mathrm{Al}_{2} \mathrm{O}_{3}$ and enhances the fast development of a dense $\alpha-\mathrm{Al}_{2} \mathrm{O}_{3}$ layer. However, the addition of $\mathrm{Ce}$ in MCrAlX coatings does not show the same positive effects as that of Y. A similar TGO microstructure can be observed on the $\mathrm{C} 1$ and $\mathrm{C} 2$ coatings after isothermal oxidation at $1100{ }^{\circ} \mathrm{C}$ for different oxidation times, as illustrated in Figure 7. It is worth mentioning that the outer alumina layer thickness of the $\mathrm{C} 2$ coating reached half of the overall alumina scale thickness at $800 \mathrm{~h}$ oxidation, indicating not only the inward growth of the inner alumina layer but also the growth of the outer layer contributing to the overall alumina scale growth in the $\mathrm{C} 2$ coating. In contrast, the influence of the outer alumina layer growth on the overall alumina growth is trivial in the $\mathrm{C} 1$ coating considering the relatively thin outer layer thickness of the $\mathrm{C} 1$ coating without much thickening after $800 \mathrm{~h}$ oxidation. 

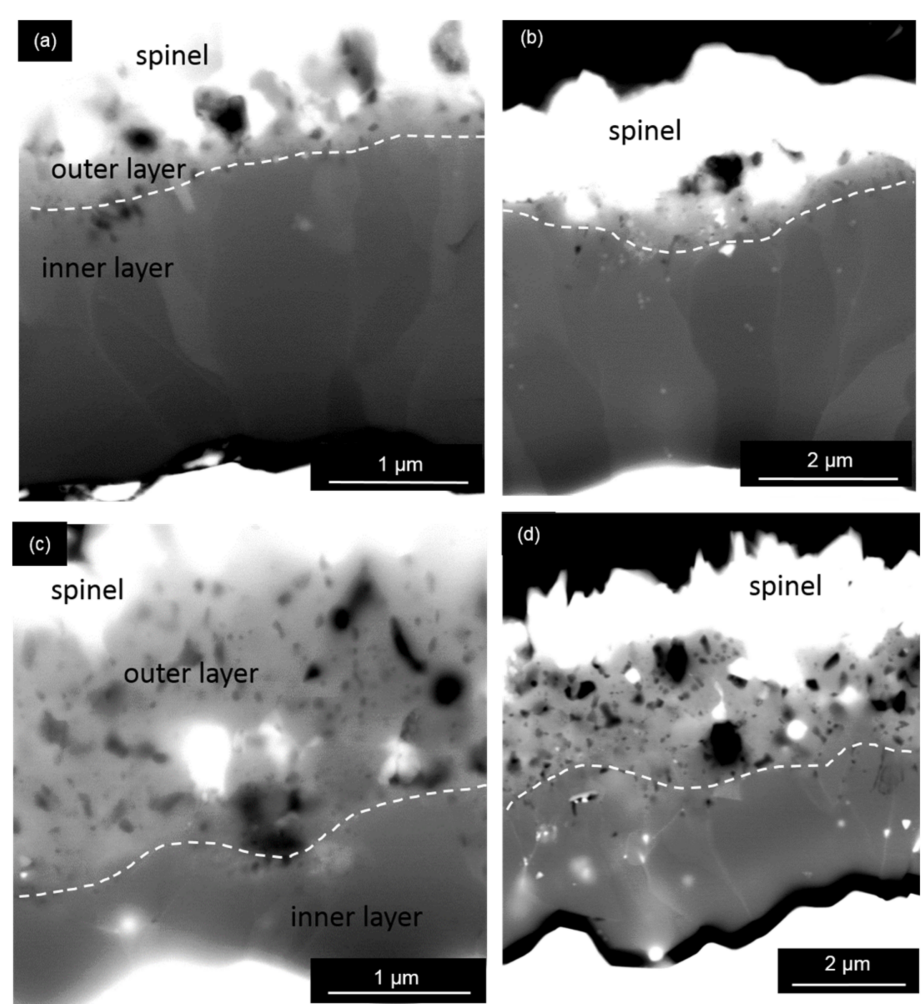

Figure 5. Cross-section of the TGO after isothermal oxidation at $1000{ }^{\circ} \mathrm{C}, \mathrm{Y}+\mathrm{Ru}$-doped $\mathrm{C} 1$ coating for $500 \mathrm{~h} \mathrm{(a)}$ and $5000 \mathrm{~h} \mathrm{(b)}$; Ce-doped C2 coating for $500 \mathrm{~h} \mathrm{(c)} \mathrm{and} 5000 \mathrm{~h}(\mathbf{d})$. White dashed lines marked the outer/inner $\mathrm{Al}_{2} \mathrm{O}_{3}$ layer boundary. (Note that the images are in different magnifications.).
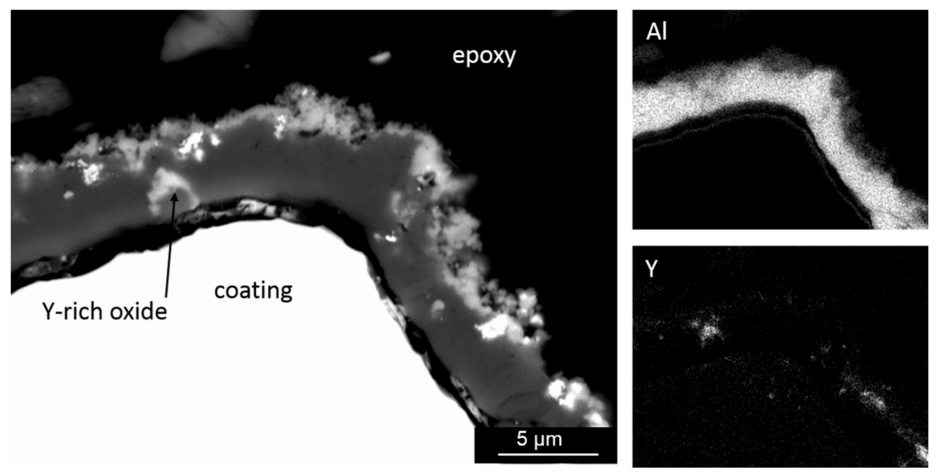

Figure 6. EDS mapping on the TGO of the $\mathrm{C} 1$ coating after isothermal oxidation at $1000{ }^{\circ} \mathrm{C}$ for $5000 \mathrm{~h}$, showing Y-rich particles.

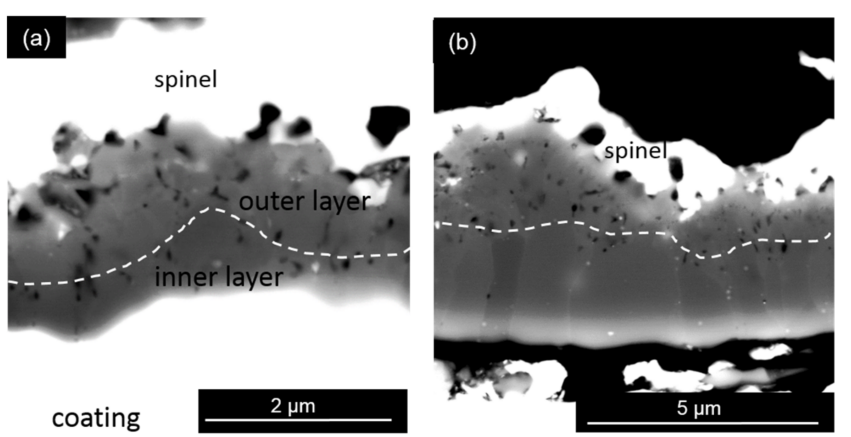

Figure 7. Cont. 


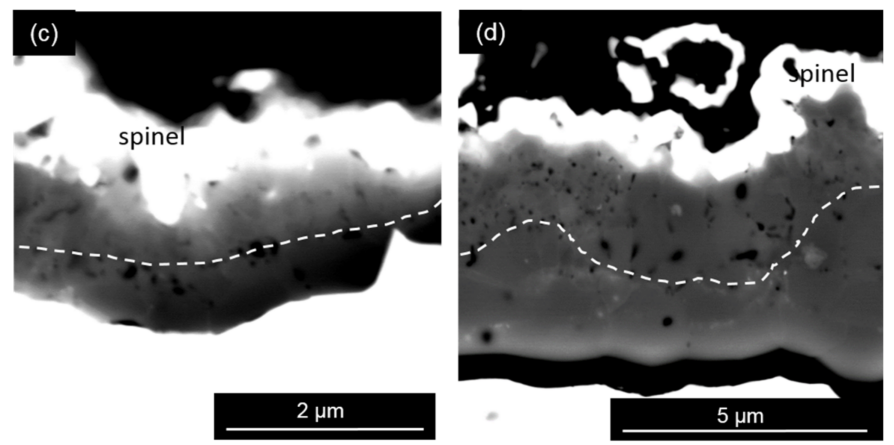

Figure 7. Cross-section of the TGO after isothermal oxidation at $1100{ }^{\circ} \mathrm{C}: \mathrm{Y}+\mathrm{Ru}$-doped $\mathrm{C} 1$ coating for $50 \mathrm{~h} \mathrm{(a)}$ and $800 \mathrm{~h} \mathrm{(b)}$; Ce-doped C2 coating for $50 \mathrm{~h} \mathrm{(c)} \mathrm{and} 800 \mathrm{~h}(\mathbf{d})$. White dashed lines marked the outer/inner $\mathrm{Al}_{2} \mathrm{O}_{3}$ layer boundary. (Note that the images are in different magnifications.).

\subsubsection{Oxidation Kinetics}

The development of the outer $\beta$ phase depletion zone (OBDZ), which appeared in the coatings below the coating-oxide interface (Figure 1), is directly connected to the loss of the Al due to surface oxidation. The OBDZ growth rate was used to represent the oxidation resistance of the coatings instead of the TGO growth rate. As is recognized, the growth of the OBDZ thickness, which represents the growth of the alumina scale, is assumed to be diffusion-controlled following a parabolic oxidation law:

$$
h=(k t)^{1 / 2}
$$

with $k$ following the Arrhenius relationship:

$$
k=k_{0} \mathrm{e}^{-\frac{Q}{R T}}
$$

where $h$ represents the OBDZ thickness, $k$ is the growth rate constant, $t$ denotes oxidation time, $Q$ is the activation energy, $T$ is temperature, and $R$ is the gas constant $8.314 \mathrm{~J} \mathrm{~mol}^{-1} \cdot \mathrm{K}^{-1}$.

Figure 8 shows the evolution of the OBDZ thickness during oxidation versus the square root of oxidation time at different temperatures. As can be seen, the fitting of the regression models shows good correspondence with the experimental data, with coefficients of determination $\left(R^{2}\right)$ higher than 0.95. At $900^{\circ} \mathrm{C}$, the OBDZ thickness is quite large at $500 \mathrm{~h}$ for the $\mathrm{C} 2$ coating, which developed slower compared with that of the $\mathrm{C} 1$ coating. It corresponds to the microstructural observation in Figure 4 that the outward growth of the transient alumina on the $\mathrm{C} 2$ coating reached a certain thickness in a short time, resulted in a fast $\mathrm{Al}$ depletion (thick OBDZ) at $500 \mathrm{~h}$. Once the transient alumina fully transformed into $\alpha-\mathrm{Al}_{2} \mathrm{O}_{3}$, the overall growth of the alumina scale shifted to inward growth of the inner alumina layer. Due to the aforementioned $\mathrm{Y}$ effect, the inner layer of the $\mathrm{C} 1$ coating grew faster than that of the $\mathrm{C} 2$ coating, where Ce shows no such effect, leading to a faster overall alumina scale growth rate of the $\mathrm{C} 1$ coating. In the case of $1000{ }^{\circ} \mathrm{C}$ oxidation (Figure 5), the growth of the inner layer dominates the overall growth of the alumina scale in the $\mathrm{C} 1$ coating. However, the growth of the outer porous layer of the $\mathrm{C} 2$ coating also contributes to the overall growth of the alumina scale, giving a similar OBDZ growth rate. At $1100{ }^{\circ} \mathrm{C}$, the larger OBDZ thickness growth rate of the $\mathrm{C} 2$ coating indicates that both the inner and outer alumina layers contribute to the overall growth rate of the alumina scale, leading to a larger growth rate of the $\mathrm{C} 2$ coating than of the $\mathrm{C} 1$ coating. 

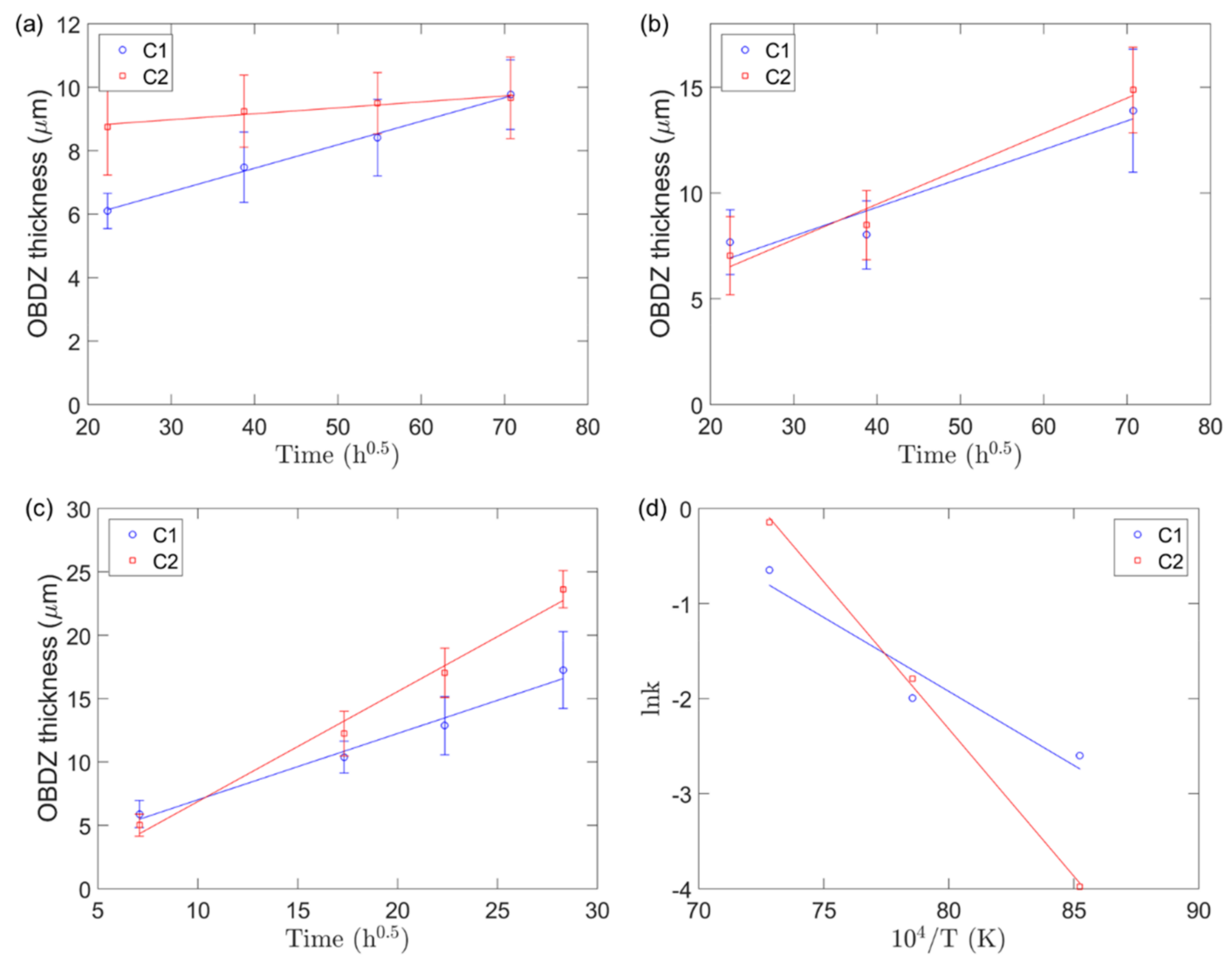

Figure 8. The outer $\beta$ phase depletion zone (OBDZ) thickness evolution of the $\mathrm{C} 1$ and $\mathrm{C} 2$ coatings after isothermal $900{ }^{\circ} \mathrm{C}(\mathbf{a}), 1000{ }^{\circ} \mathrm{C}(\mathbf{b})$, and $1100{ }^{\circ} \mathrm{C}(\mathbf{c})$ oxidation test. (d) Arrhenius relationship: $\ln (k)$ of the $\mathrm{C} 1$ and $\mathrm{C} 2$ coatings for the isothermal oxidation at 900,1000 , and $1100{ }^{\circ} \mathrm{C}$ vs. $10^{4} / \mathrm{T}$.

The temperature dependence of the OBDZ thickness growth rate constants were obtained from the slope of straight lines by fitting Equation (1) to the experimentally determined OBDZ thickness growth data in Figure 8a-c. It is apparent that the evolution of the OBDZ thickness of the $\mathrm{C} 1$ and $\mathrm{C} 2$ coatings follows the Arrhenius type (see Equation (2)) temperature. In Figure $8 \mathrm{~d}$ the logarithm of the OBDZ rate constants $\mathrm{k}$ of the $\mathrm{C} 1$ and $\mathrm{C} 2$ coatings were plotted versus the inverse of temperature $10^{4} / \mathrm{T}$. Both rate constants are in good agreement with this experiment range. It reflects the growth of the $\mathrm{Al}_{2} \mathrm{O}_{3}$ scale, since the $\mathrm{Al}$ in the OBDZ is mostly consumed through the formation of the alumina scale. From the slope in Figure 8d, the activation energy of OBDZ growth was found to be approximately $311 \mathrm{~kJ} / \mathrm{mol}$ for the $\mathrm{C} 1$ coating. It is noted that the activation energy of the $\mathrm{C} 1$ coating is comparable with the activation energy of the $\alpha-\mathrm{Al}_{2} \mathrm{O}_{3}$ growth of sputtered $\mathrm{NiCrAlY}(390 \mathrm{~kJ} / \mathrm{mol})$ [39] and that of $\mathrm{NiAl}(382 \mathrm{~kJ} / \mathrm{mol})$ [31]; however, it considerably less than that of the Al lattice diffusion in the $\mathrm{Al}_{2} \mathrm{O}_{3}$ $(\sim 500 \mathrm{~kJ} / \mathrm{mol})$ [40]. Most evidence indicates that the growth of the $\mathrm{Al}_{2} \mathrm{O}_{3}$ scale of the $\mathrm{C} 1$ coating is dominated by the grain-boundary diffusion of oxygen [39]. Also, the presence of $Y$ may reduce the kinetics of the $\mathrm{Al}$ lattice diffusion, which has been reported in reference [41]. However, the activation energy of the $\mathrm{C} 2$ coating is $619 \mathrm{~kJ} / \mathrm{mol}$, which is even higher than the activation energy of the $\mathrm{Al}$ lattice diffusion in the $\mathrm{Al}_{2} \mathrm{O}_{3}$. It can be explained that the growth of the outer transient alumina layer has a great impact on the overall growth of the alumina scale in the $\mathrm{C} 2$ coating, indicated by the relatively thick outer alumina layer of the $\mathrm{C} 2$ coating at different oxidation temperatures. The shifting of the dominant growth mechanisms from the outward growth of the outer layer to inward growth of the inner layer in the $\mathrm{C} 2$ coating alters the growth rate of the $\mathrm{C} 2$ coating, especially at $900{ }^{\circ} \mathrm{C}$, which causes a deep slope in Figure 8, giving a much higher activation energy of the $\mathrm{C} 2$ coating. Thus, the addition of $Y$ suppresses the growth of the outer layer and modifies the overall alumina growth mechanism. 
In contrast, the addition of Ce does not modify the alumina scale growth, leading to a mutual growth of both the outer and inner alumina layers and therefore a much higher oxidation activation energy.

\subsubsection{Cyclic Oxidation Resistance}

The spallation of the oxide scale will accelerate the consumption of $\mathrm{Al}$, which leads to fast depletion of the $\beta$ phase in the coating, and thus, a comparison of the OBDZ growth rate between the isothermal and cyclic oxidation tests can be used to evaluate the spallation resistance of the oxide scale. Figure 9a,b show the OBDZ thickness changes of the $\mathrm{Y}+\mathrm{Ru}$-doped $\mathrm{C} 1$ coating and the Ce-doped $\mathrm{C} 2$ coating during cyclic oxidation testing at $1100{ }^{\circ} \mathrm{C}$ and isothermal oxidation testing at $1100{ }^{\circ} \mathrm{C}$, respectively. The results were obtained by measuring the thickness evolution of the OBDZ with oxidation time.
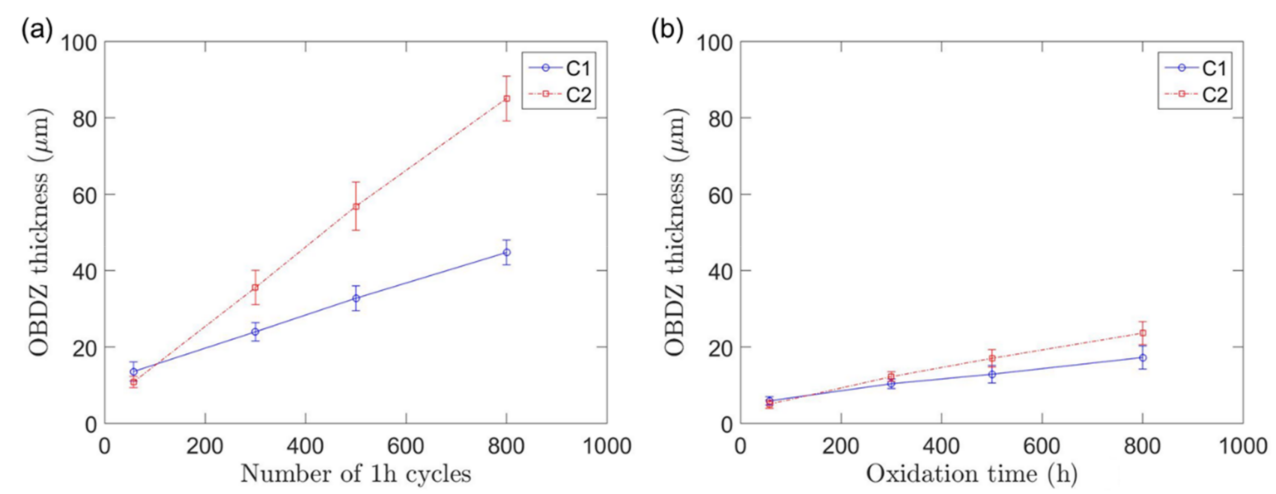

Figure 9. The $\mathrm{OBDZ}$ thickness of the $\mathrm{C} 1$ and $\mathrm{C} 2$ coatings after cyclic oxidation testing at $1100{ }^{\circ} \mathrm{C}(\mathbf{a})$ and isothermal oxidation testing at $1100{ }^{\circ} \mathrm{C}(\mathbf{b})$.

From Figure 9, it can be observed that for the C2 coating the OBDZ thickness after 800 cycles in the cyclic oxidation test $(85.1 \pm 5.9 \mu \mathrm{m})$ was 3.6 folders of that after $800 \mathrm{~h}$ of the isothermal oxidation test $(23.6 \pm 1.5 \mu \mathrm{m})$. For the $\mathrm{C} 1$ coating, the OBDZ thickness difference between the isothermal oxidation $(17.2 \pm 3.0 \mu \mathrm{m})$ and the cyclic oxidation $(44.7 \pm 3.3 \mu \mathrm{m})$ was much smaller. As no obvious TGO spallation was observed under the isothermal oxidation test, the accelerated OBDZ growth rate observed in the cyclic oxidation test for both coatings was mainly related to TGO spallation due to thermal stresses induced by the temperature changes. The much larger OBDZ thickness of the C2 coating, twice of that of the $\mathrm{C} 1$ coating, after 800 cycles indicated a poorer spallation resistance of the former. There is no doubt that a significant difference exists between $\mathrm{Y}+\mathrm{Ru}$ and Ce dopants in improving the scale adhesion. Ogawa et al. [42] observed root-like oxide precipitates in the TGO in coatings containing $\mathrm{Ce}$, which improved the TGO adhesion due to an anchor effect, and the influence was found to become more pronounced when the amount of Ce increased. However, no such root-like oxide precipitates were found in the TGO in the Ce-doped C2 coating. This could be due to a too small amount of Ce addition ( $0.2 \mathrm{wt} \%)$ compared with Ogawa's work $(0.5,1,1.5 \mathrm{wt} \%)$. Therefore, considering its poor isothermal oxidation and cyclic oxidation resistance, the $\mathrm{C} 2$ coating with $0.2 \mathrm{wt} \%$ Ce doping could not provide as good oxidation resistance as $0.3 \mathrm{wt} \%$ Y-doped C1 coating.

\subsection{Simulation Results}

Because no Ru can be identified in the TGO layer, and the Ru-oxide formation energy is low $(94.25 \mathrm{~kJ} / \mathrm{mol})$ compared to that of the $\mathrm{Al}_{2} \mathrm{O}_{3}(847.25 \mathrm{~kJ} / \mathrm{mol})$ at $1000{ }^{\circ} \mathrm{C}$, it is reasonable to assume that $\mathrm{Ru}$ has no direct influence on the surface oxidation of the coatings. The beneficial effect of Ru on prolonging the coating lifetime derives from its effect on reducing the loss of the $\mathrm{Al}$ to the substrate through interdiffusion, which was observed in the $\mathrm{C} 1$ coating. As Figure 1 shows, the inner $\beta$ phase 
depletion zone in the $\mathrm{C} 1$ coating is much smaller than that in the $\mathrm{C} 2$ coating. Results from the different simulations to explore the mechanisms behind the Ru effect are presented below.

\subsubsection{Phase Equilibrium Calculation}

Because the simulation is based on the combination of diffusion and phase equilibrium calculation, the effect of $\mathrm{Ru}$ on the interdiffusion was further investigated by phase equilibrium calculation using Thermo-Calc, see Figure 10. Several different alloy systems with similar compositions to the $\mathrm{C} 1$ coating

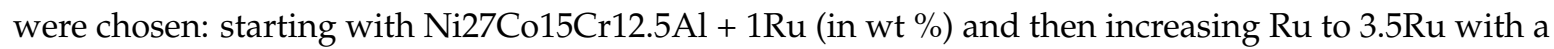
step size of $0.5 \mathrm{wt} \%$ of $\mathrm{Ru}$ at the expense of $\mathrm{Ni}$. It is clear that the $\beta$ phase fraction decreased with the decreasing Ru concentration in the alloy, from $74 \%$ to $71.5 \%$ at $1100{ }^{\circ} \mathrm{C}$, indicating that Ru stabilizes the $\beta$ phase in the alloy systems. This result is consistent with [23], which claimed that Ru greatly stabilizes the $\beta$ phase by largely extending the $\beta$ phase field in the phase diagram.

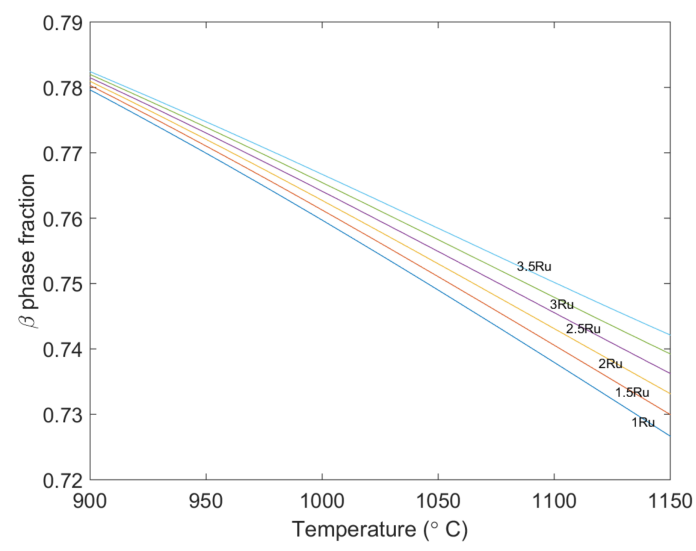

Figure 10. $\beta$ phase fraction for different alloy system from 900 to $1150{ }^{\circ} \mathrm{C}$, derived from the equilibrium calculation by Thermo-Calc. The composition of the alloy systems is Ni27Co15Cr12.5Al + 1Ru, 1.5Ru, $2 \mathrm{Ru}, 2.5 \mathrm{Ru}, 3 \mathrm{Ru}, 3.5 \mathrm{Ru}$.

\subsubsection{Short-Range Diffusion}

The moving phase boundary model was applied to simulate short-range diffusion through the $\gamma / \beta$ phase boundary in the coating for two coating systems, named S1 and S2, under high temperature exposure. The chemical composition of the $\gamma$ and $\beta$ phases in S1 and S2, given in Table 3, were based on EDS measurements of the heat-treated coating C1 and C2, respectively. The chemical gradient of other minor elements, such as $\mathrm{Si}, \mathrm{Mo}$, and Ta was neglected in order to highlight the influence of $\mathrm{Ru}$ on the short-range diffusion between the $\gamma$ and $\beta$ phases and to accelerate the simulation speed as well.

Table 3. The composition (wt \%) of $\gamma$ and $\beta$ phase in the S1 and S2 systems for short-range diffusion modelling.

\begin{tabular}{ccccccc}
\hline Coating & Phase & Ni & Co & Cr & Al & Ru \\
\hline \multirow{2}{*}{ S1 } & $\gamma$ & 36.3 & 33.3 & 24.7 & 3.8 & 1.9 \\
& $\beta$ & 51.5 & 17.3 & 7.4 & 17.5 & 6.3 \\
\hline \multirow{2}{*}{ S2 } & $\gamma$ & 41.5 & 32.4 & 22 & 4.1 & - \\
& $\beta$ & 56.8 & 18.6 & 6.8 & 17.8 & - \\
\hline
\end{tabular}

Figure 11 shows the interfacial position (phase boundary) movement of the S1 and S2 systems with time for up to $10^{7} \mathrm{~s}$ at $1100{ }^{\circ} \mathrm{C}$ (Note that the original phase boundary for both S1 and S2 were at $5.5 \mu \mathrm{m}$ and $800 \mathrm{~h}$ is $2.88 \times 10^{6} \mathrm{~s}$ ). It can be seen that the interfacial position of both S1 and S2 changed with time and reached a new equilibrium state after $10^{5} \mathrm{~s}$ because there was no interference from outside the system. Comparing S1 and S2, the interfacial position moved by $0.4 \mu \mathrm{m}$ towards the $\gamma$ 
phase region for S1 but $0.8 \mu \mathrm{m}$ towards the $\beta$ phase region for S2. This means that the $\beta$ phase region had the tendency to grow in S1 but to shrink in S2.

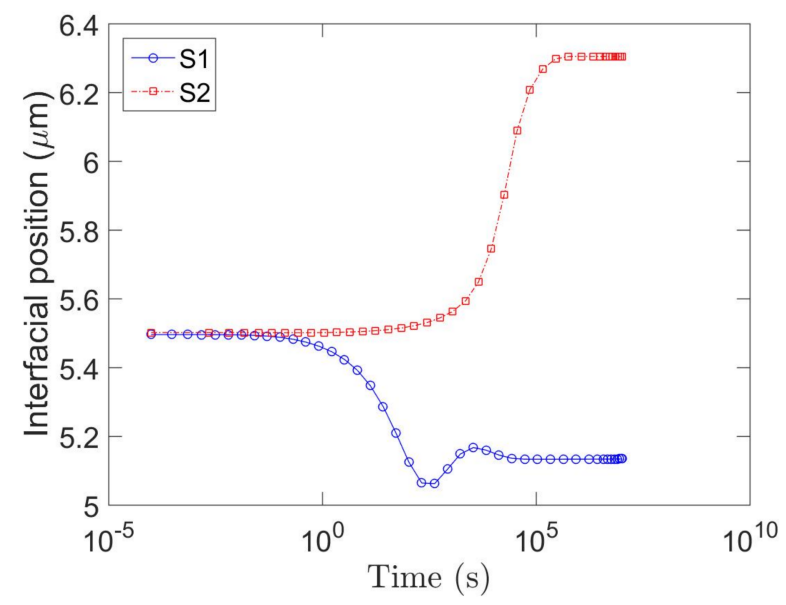

Figure 11. The movement of $\gamma / \beta$ phase region interfacial position from the $\gamma$ phase region $(0-5.5 \mu \mathrm{m})$ into the $\beta$ phase region $(5.5-10 \mu \mathrm{m})$ at $1100{ }^{\circ} \mathrm{C}$, the original phase boundary was at $5.5 \mu \mathrm{m}$.

Figure 12 shows the calculated $\mathrm{Al}$ concentration profiles of the $\mathrm{S} 1$ and $\mathrm{S} 2$ systems at $0 \mathrm{~s}$ and $10^{5} \mathrm{~s}$, the $\mathrm{Al}$ concentration profiles at other times were not included, as they were close to the data at $10^{5} \mathrm{~s}$. The $\gamma$ phase region and $\beta$ phase region were arranged from left to right in the moving phase boundary model, and the interface was set at a distance of $5.5 \mu \mathrm{m}$. The concentration of the $\mathrm{Al}$ in $\beta$ decreased with increasing time in both systems. For the S1 (Figure 12a), the Al concentration in $\gamma$ increased only by $0.6 \mathrm{wt} \%$ along with the decrease of the $\mathrm{Al}$ in $\beta$, and the expanding of the $\beta$ phase region indicates only a small amount of the Al diffused from $\beta$ into $\gamma$. For the S2 (Figure 12b), however, the diffusion of the $\mathrm{Al}$ from $\beta$ into $\gamma$ led to an increase of the $\mathrm{Al}$ by $1.8 \mathrm{wt} \%$ in the $\gamma$ phase. According to the Thermo-Calc calculation, the Al diffusivity in the $\gamma$ phase is $4.9 \times 10^{-13} \mathrm{~m}^{2} / \mathrm{s}$ and in the $\beta$ phase is $9.7 \times 10^{-14} \mathrm{~m}^{2} / \mathrm{s}$, for S1 and S2, respectively. Hence, from the analysis above, the $\mathrm{Al}$ in the S2 system diffused from $\beta$ into $\gamma$ rapidly, which means the inward diffusion of the $\mathrm{Al}$ from the coating to the substrate is faster in S2 as the Al diffusivity in the $\gamma$ phase is higher than in the $\beta$ phase. Thus, the addition of $\mathrm{Ru}$ in the $\mathrm{C} 1$ coating stabilizes $\beta$ and slows down $\beta$ phase depletion.
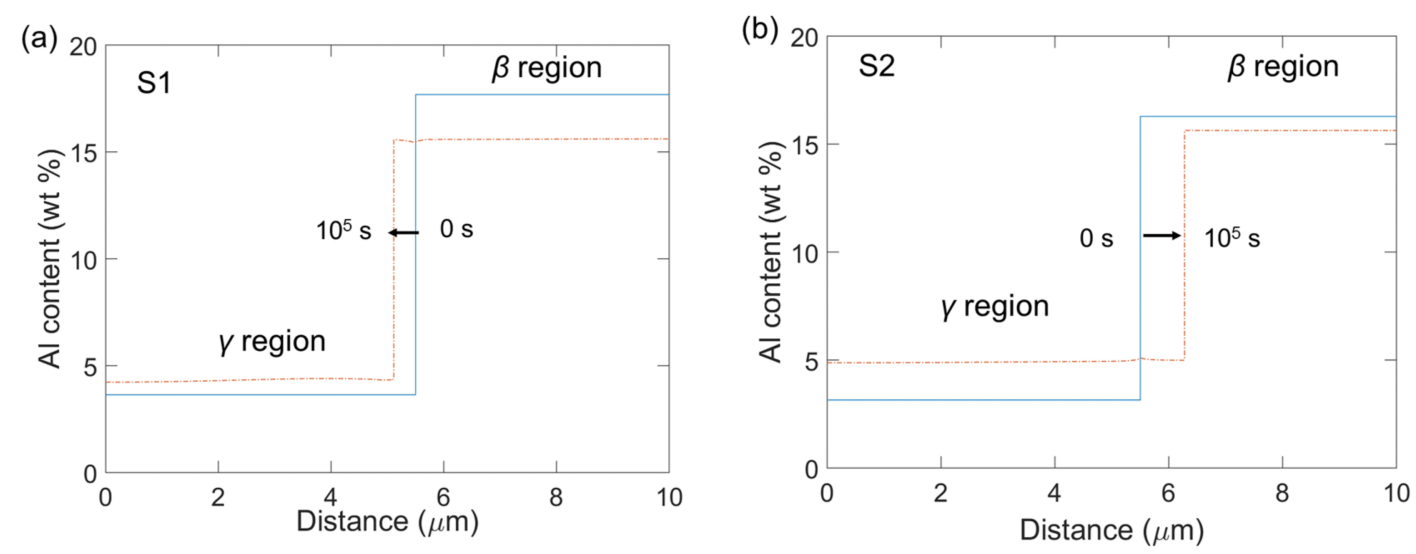

Figure 12. Al concentration profile of $\mathrm{S} 1(\mathbf{a})$ and $\mathrm{S} 2(\mathbf{b})$ at $0 \mathrm{~s}$ and $10^{5} \mathrm{~s}$ simulation time from the moving phase boundary modelling. Al concentration profiles at other times were not included here for they were close to the data at $10^{5} \mathrm{~s}$. The $\gamma$ phase region and $\beta$ phase region were arranged from left to right with the interface at distance $=5.5 \mu \mathrm{m}$. 
The difference of the $\mathrm{Al}$ solubility in $\beta$ phase of the $\mathrm{C} 1$ and $\mathrm{C} 2$ coating can be explained with the Ru effect. The Al and Ru concentrations in the $\gamma$ and $\beta$ phases from the EDS measurements on the $\mathrm{C} 1$ and $\mathrm{C} 2$ coatings after heat treatment are listed in Table 4 . A slightly higher Al concentration was shown for the $\mathrm{C} 2$ coating containing Ce. The influence of $\mathrm{Ru}$ on the $\mathrm{Al}$ solubility in the $\beta$ phase at various temperatures was also calculated using Thermo-Calc, and the initial composition of the $\mathrm{C} 1$ coating was the input. The results shown in Figure 13 are the projection of a three-dimensional diagram with the weight percent of the $\mathrm{Al}$ and $\mathrm{Ru}$, namely the solubility of the $\mathrm{Al}$ and $\mathrm{Ru}$, in the $\beta$ phase as $x$ - and $y$-axes and temperature as $z$-axis. The temperature was marked selectively in the diagram. The solubility of the $\mathrm{Al}$ increased with increasing Ru solubility, from $17.6 \mathrm{wt} \%$ at $1200{ }^{\circ} \mathrm{C}$ to $18.15 \mathrm{wt} \%$ at $1080{ }^{\circ} \mathrm{C}$, and reached $17.94 \mathrm{wt} \%$ at the maximum solubility of $\mathrm{Ru}, 6.56 \mathrm{wt} \%$ in $\beta$. According to the equilibrium calculation, the increasing enrichment of $\mathrm{Ru}$ in the $\beta$ phase will enlarge the solubility range of the $\mathrm{Al}$ in the $\beta$ phase. Thus, the increasing amount of $\mathrm{Ru}$ in the $\beta$ phase would aid the partition of the $\mathrm{Al}$ in $\beta$ phase.

Table 4. Al and $\mathrm{Ru}$ concentration (wt \%) in $\gamma$ and $\beta$ phase from the EDS measurement on samples oxidized at $1100{ }^{\circ} \mathrm{C}$. (Ratio $=$ element concentration in phase/average value).

\begin{tabular}{cccccc}
\hline \multirow{2}{*}{ Element } & \multirow{2}{*}{ Average Content Measured in the Coatings } & \multicolumn{2}{c}{$\gamma$} & \multicolumn{3}{c}{$\beta$} \\
\cline { 3 - 6 } & & $\mathbf{w t} \%$ & Ratio & wt \% & Ratio \\
\hline $\mathrm{Al}$ (in C1) & 11.5 & 3.8 & 0.33 & 17.5 & 1.52 \\
$\mathrm{Al}$ (in C2) & 12 & 4.1 & 0.34 & 17.8 & 1.48 \\
$\mathrm{Ru}$ (in C1) & 3.7 & 1.9 & 0.41 & 6.3 & 1.62 \\
\hline
\end{tabular}

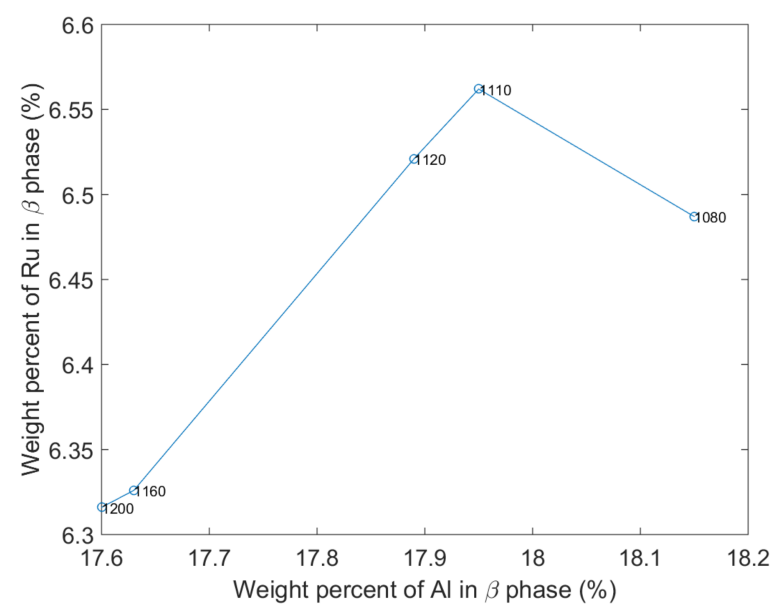

Figure 13. Projection of three-dimensional diagram with the weight percent of the $\mathrm{Al}$ in the $\beta$ phase $-x$-axis, Ru in $\beta$ phase $-y$-axis and temperature $-z$-axis. The temperature corresponding to each point has been marked.

\subsubsection{Long-Range Diffusion}

Interdiffusion between the coating and substrate can result in $\beta$-depletion near the coating-substrate interface on the coating side (Figure 3) as aluminum moves from the coating to the substrate. The $\beta$ phase depletion rate, controlled by diffusion, is expected to follow Equation (1). To demonstrate the Ru effect on the phase equilibrium and diffusion, which has been mentioned in previous sections, the long-range diffusion between the coating and the substrate were simulated using the oxidation-diffusion model by studying the $\beta$ phase depletion rate.

Figure 14a shows the simulation results of the $\beta$ phase depletion for the $Y+R u$-doped $C 1$ coating at $1100{ }^{\circ} \mathrm{C}$. Simulation was also performed for the $\mathrm{C} 2$ coating but the results are not presented here. Figure $14 \mathrm{~b}$ shows both the isothermal $1100{ }^{\circ} \mathrm{C}$ oxidation test data and simulation data of the IBDZ 
(inner $\beta$-depletion zone, Figure 14a) thickness versus square root of time. The IBDZ growth rates of the $C 1$ and $C 2$ coatings were 1.44 and $2.17 \mu \mathrm{m} / \mathrm{h}^{0.5}$, respectively, which were consistent with the simulation results $\left(1.52 \mu \mathrm{m} / \mathrm{h}^{0.5}\right.$ for $\mathrm{C} 1$ and $2.05 \mu \mathrm{m} / \mathrm{h}^{0.5}$ for C2). Thus, both the simulation and experimental analyses showed that the addition of $\mathrm{Ru}$ in the $\mathrm{C} 1$ coating decreased interdiffusion induced $\beta$ phase depletion. The DICTRA simulation is based on the coupling phase equilibrium calculation and the solving of Fick's law on each small-time steps and nodes. The element diffusivity data in oxidation-diffusion model is essential to solving the Fick's law, which derived from the calculation of the effective diffusivity of each element according to homogenization model 5 in DICTRA. Thus, the long-range diffusion simulation is actually the comprehensive coupling of element effect on both the phase equilibrium and diffusion behavior. Since the simulation results agreed well with the experimental results and the IBDZ growth rate of the $\mathrm{C} 1$ coating is lower than that of the $\mathrm{C} 2$ coating, the profound effect of Ru on stabilizing the $\beta$ phase and its effect on decreasing short-range diffusion can be proved by the long-range diffusion simulation. Therefore, the Ru effect on retarding the long-range diffusion of the $\mathrm{Al}$ between the coating and the substrate can be inferred.

(a)

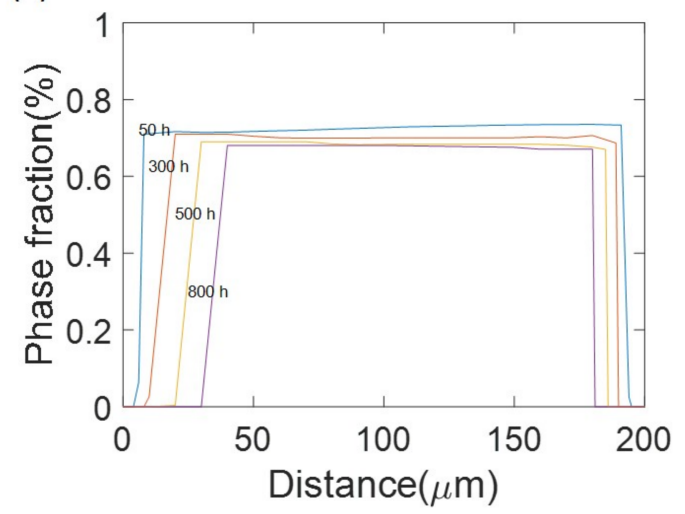

(b)

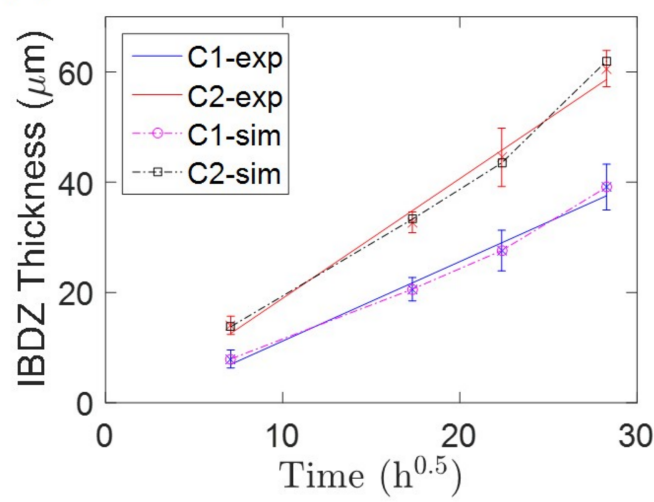

Figure 14. Simulation results of the $\beta$ phase evolution of $Y+R u$-doped $C 1$ coating at $1100{ }^{\circ} \mathrm{C}(\mathbf{a})$. IBDZ thickness data of the $\mathrm{C} 1$ and $\mathrm{C} 2$ coating from the isothermal oxidation test and simulation at $1100{ }^{\circ} \mathrm{C}$ plotted versus square root of time (b) (the dotted line and solid line represented simulation results and the isothermal oxidation test data, respectively).

In summary, the simulations on both short-range and long-range diffusion demonstrated that $\mathrm{Ru}$ addition in the NiCoCrAlX coating increased the Al solubility in the $\beta$ phase, as well as the $\beta$ phase fraction. Due to a higher diffusivity of the $\mathrm{Al}$ in $\gamma$ phase than in $\beta$ phase, these two effects contributed to the stabilization of the $\beta$ phase and the slowdown of the inward diffusion of the $\mathrm{Al}$ from the coating to the substrate.

\section{Conclusions}

Oxidation behavior of NiCoCrAlX coatings with Ce and $\mathrm{Y}+\mathrm{Ru}$ additions was compared in different test conditions. Conclusions can be drawn as follows:

A two-layer structure alumina scale developed in the TGO of both the $\mathrm{Y}+\mathrm{Ru}$-doped coating and Ce-doped coating: an outer porous outward-grown layer, and an inner inward-grown layer. The continued growth of the outer and inner $\mathrm{Al}_{2} \mathrm{O}_{3}$ layer depleted the $\mathrm{Al}$ from the coatings, and the growth behavior of the two layers differed at different temperatures, which is also dependent on coating composition.

- Comparison of the activation energy for the OBDZ growth with that for the Al lattice diffusion in $\mathrm{Al}_{2} \mathrm{O}_{3}$ indicates that the growth of the alumina scale in the $\mathrm{Y}+\mathrm{Ru}$-doped coating is dominated by grain boundary diffusion of oxygen with the positive effect of $Y$ to increase the growth 
kinetics of the alumina scale. However, the Ce-doped coating shows a different alumina scale growth kinetics.

- In comparison with the Ce-doped coating, the $\mathrm{Y}+\mathrm{Ru}$-doped coating showed a lower growth rate of the outer $\beta$-depletion zone (beneath the protective scale) in both isothermal $1100{ }^{\circ} \mathrm{C}$ and cyclic oxidation tests, indicating a better resistance to oxide growth and a stronger adhesion of the TGO. The spallation of the alumina scale in the Ce-doped coating at $1100{ }^{\circ} \mathrm{C}$ accelerated the consumption of the $\mathrm{Al}$ in the coating.

- The addition of $Y$ in MCrAlX coatings plays an important role during coating oxidation, including modifying alumina growth mechanisms, aiding the columnar alumina microstructure formation, and increasing alumina scale adhesion against spallation. However, none of such positive effects can be observed by the addition of $0.2 \mathrm{wt} \% \mathrm{Ce}$ in the MCrAlX coating. Therefore, it is reasonable to assume that the addition of $0.2 \mathrm{wt} \%$ Ce cannot replace the important role of $Y$ in MCrAlX coatings.

- The $\mathrm{Y}+\mathrm{Ru}$-doped coating exhibited a lower growth rate of inner $\beta$-depletion zone (near the coating-substrate interface) induced by interdiffusion. The simulation results show that the addition of $\mathrm{Ru}$ increases the solubility of the $\mathrm{Al}$ in the $\beta$ phase and the $\beta$ phase fraction, which reduces the loss of the $\mathrm{Al}$ due to interdiffusion and stabilizes the $\beta$ phase.

While the addition of about $3.3 \mathrm{wt} \% \mathrm{Ru}$ in $\mathrm{Ru}+\mathrm{Y}$-doped coating seems to significantly increase resistance against substrate interdiffusion, the substitution of $Y(0.3 \mathrm{wt} \%)$ by a similar amount of Ce $(0.2 \mathrm{wt} \%)$ greatly decreases the oxidation resistance at the coating surface.

Acknowledgments: The author would like to greatly acknowledge the Siemens Industrial Turbomachinery $\mathrm{AB}$ (Finspång, Sweden) for all contributions to this project and the Swedish Energy Agency through the KME consortium-ELFORSK-for their financial support. The project teams at Linköping University are also acknowledged for their support on this research.

Author Contributions: Pimin Zhang and Ru Lin Peng conceived and designed the experiments; Pimin Zhang and Xin-Hai Li performed the experiments; Pimin Zhang analyzed the data; Ru Lin Peng and Sten Johansson contributed reagents/materials/analysis tools; and Pimin Zhang wrote the paper.

Conflicts of Interest: The authors declare no conflict of interest.

\section{References}

1. Brandl, W.; Toma, D.; Krüger, J.; Grabke, H.J.; Matthäus, G. The oxidation behaviour of HVOF thermal-sprayed MCrAlY coatings. Surf. Coat. Technol. 1997, 94-95, 21-26. [CrossRef]

2. Chen, L.C.; Zhang, C.; Yang, Z.G. Effect of pre-oxidation on the hot corrosion of CoNiCrAlYRe alloy. Corros. Sci. 2011, 53, 374-380. [CrossRef]

3. Smeggil, J.G. Some comments on the role of yttrium in protective oxide scale adherence. Mater. Sci. Eng. 1987, 87, 261-265. [CrossRef]

4. Stott, F.H.; Wood, G.C. Growth and adhesion of oxide scales on $\mathrm{Al}_{2} \mathrm{O}_{3}$-forming alloys and coatings. Mater. Sci. Eng. 1987, 87, 267-274. [CrossRef]

5. Pint, B.A.; More, K.L.; Wright, I.G. Effect of quaternary additions on the oxidation behavior of Hf-doped NiAl. Oxid. Met. 2003, 59, 257-283. [CrossRef]

6. Guo, H.; Cui, Y.; Peng, H.; Gong, S. Improved cyclic oxidation resistance of electron beam physical vapor deposited nano-oxide dispersed $\beta$-NiAl coatings for Hf-containing superalloy. Corros. Sci. 2010, 52, 1440-1446. [CrossRef]

7. Taylor, T.A.; Bettridge, D.F. Development of alloyed and dispersion-strengthened MCrAlY coatings. Surf. Coat. Technol. 1996, 86-87, 9-14. [CrossRef]

8. Czech, N.; Schmitz, F.; Stamm, W. Improvement of MCrAlY coatings by addition of rhenium. Surf. Coat. Technol. 1994, 68-69, 17-21. [CrossRef]

9. Mevrel, R. Cyclic oxidation of high-temperature alloys. Mater. Sci. Technol. 1987, 3, 531-535. [CrossRef]

10. Tanno, M.; Ogawa, K.; Shoji, T. Effect of cerium and silicon additions to MCrAlY on the high-temperature oxidation behavior and bond strength of thermal barrier coatings. Key Eng. Mater. 2004, 261-263, 1061-1066. [CrossRef] 
11. Amano, T.; Taguchi, T. Spalling of the surface oxide formed on Ni-(20,40,60,80)Cr alloys with small additions of Ce and Si. J. Alloys Compd. 1993, 193, 20-22. [CrossRef]

12. Itoh, Y.; Tamura, M. Reaction diffusion behaviors for interface between Ni-based super alloys and vacuum plasma sprayed MCrAlY coatings. Eng. Gas Turbines Power 1999, 121, 476-483. [CrossRef]

13. Yuan, K.; Eriksson, R.; Peng, R.L.; Li, X.H.; Johansson, S.; Wang, Y.D. MCrAlY coating design based on oxidation-diffusion modelling. Part I: Microstructural evolution. Surf. Coat. Technol. 2014, 254, 79-96. [CrossRef]

14. Salam, S.; Hou, P.; Zhang, Y.-D.; Wang, H.-F.; Zhang, C.; Yang, Z.-G. Compositional effects on the high-temperature oxidation lifetime of MCrAlY type coating alloys. Corros. Sci. 2015, 95, 143-151. [CrossRef]

15. Wang, Y.; Guo, H.; Peng, H.; Peng, L.; Gong, S. Diffusion barrier behaviors of (Ru,Ni)Al/NiAl coatings on Ni-based superalloy substrate. Intermetallics 2011, 19, 191-195. [CrossRef]

16. Sato, A.; Harada, H.; Yokokawa, T.; Murakumo, T.; Koizumi, Y.; Kobayashi, T.; Imai, H. The effects of ruthenium on the phase stability of fourth generation Ni-base single crystal superalloys. Scr. Mater. 2006, 54, 1679-1684. [CrossRef]

17. Nijdam, T.J.; Sloof, W.G. Effect of reactive element oxide inclusions on the growth kinetics of protective oxide scales. Acta Mater. 2007, 55, 5980-5987. [CrossRef]

18. Luthra, K.L.; Briant, C.L. Mechanism of adhesion of alumina on MCrAlY alloys. Oxid. Met. 1986, 26, 397-416. [CrossRef]

19. Yuan, K.; Peng, R.L.; Li, X.H.; Johansson, S.; Wang, Y.D. Some aspects of elemental behaviour in HVOF MCrAlY coatings in high-temperature oxidation. Surf. Coat. Technol. 2015, 261, 86-101. [CrossRef]

20. Yuan, K.; Eriksson, R.; Peng, R.L.; Li, X.H.; Johansson, S.; Wang, Y.D. Modeling of microstructural evolution and lifetime prediction of MCrAlY coatings on nickel based superalloys during high temperature oxidation. Surf. Coat. Technol. 2013, 232, 204-215. [CrossRef]

21. Eriksson, R.; Yuan, K.; Li, X.; Peng, R.L. MCrAlY coating design based on oxidation-diffusion modelling. Part II: Lifing aspects. Surf. Coat. Technol. 2014, 253, 27-37. [CrossRef]

22. Yang, J.; Zheng, Q.; Zhang, H.; Sun, X.; Guan, H.; Hu, Z. Effects of heat treatments on the microstructure of IN792 alloy. Mater. Sci. Eng. A 2010, 527, 1016-1021. [CrossRef]

23. Saeidi, S.; Voisey, K.T.; McCartney, D.G. The effect of heat treatment on the oxidation behavior of HVOF and VPS CoNiCrAlY coatings. J. Therm. Spray Technol. 2009, 18, 209-216. [CrossRef]

24. TCS Ni-Based Superalloys Database, version 8; Thermo-Calc Software: Solna, Sweden, 2015.

25. TCS Ni-Alloys Mobility Database, version 4; Thermo-Calc Software: Solna, Sweden, 2015.

26. Andersson, J.O.; Helander, T.; Hoglund, L.; Shi, P.; Sundman, B. Thermo-Calc \& DICTRA computational tools for materials science. Calphad 2002, 26, 273-312. [CrossRef]

27. Larsson, H.; Reed, R.C. On the numerical simulation of diffusion-controlled reactions under local equilibrium conditions. Acta Mater. 2008, 56, 3754-3760. [CrossRef]

28. Larsson, H. A model for 1D multiphase moving phase boundary simulations under local equilibrium conditions. Calphad 2014, 47, 1-8. [CrossRef]

29. Toscano, J.; Vaben, R.; Gil, A.; Subanovic, M.; Naumenko, D.; Singheiser, L.; Quadakkersa, W.J. Parameters affecting TGO growth and adherence on MCrAlY-bond coats for TBC's. Surf. Coat. Technol. 2006, 201, 3906-3910. [CrossRef]

30. Liu, X.; Huang, L.; Bao, Z.B.; Wei, H.; Sun, X.F.; Guan, H.R.; Hu, Z.Q. Oxidation behavior of graded NiCrAlYRe coatings at 900, 1000 and $1100{ }^{\circ} \mathrm{C}$. Oxid. Met. 2009, 71, 125-142. [CrossRef]

31. Brumm, M.W.; Grabke, H.J. The oxidation behaviour of NiAl-I. Phase transformations in the alumina scale during oxidation of NiAl and NiAl-Cr alloys. Corros. Sci. 1992, 33, 1677-1690. [CrossRef]

32. Rybicki, G.C.; Smialek, J.L. Effect of the theta-alpha- $\mathrm{Al}_{2} \mathrm{O}_{3}$ transformation on the oxidation behavior of beta-NiAl + Zr. Oxid. Met. 1989, 31, 275-304. [CrossRef]

33. Doychak, J.; Smialek, J.L.; Barrett, C.A. The oxidation of Ni-rich Ni-Al intermetallics. In Oxidation of High-Temperature Intermetallics, Proceedings of the Workshop on the Oxidation of High-Temperature Intermetallics, Cleveland, OH, USA, 22-23 September 1988; Grobstein, T., Doychak, J.K., Eds.; TMS: Pittsburgh, PA, USA, 1989; pp. 41-55.

34. Pint, B.A. On the Formation of Interfacial and Internal Voids in a- $\mathrm{Al}_{2} \mathrm{O}_{3}$ Scales. Oxid. Met. 1997, 48, $24-27$. [CrossRef] 
35. Brady, M.P.; Pint, B.A.; Tortorelli, P.F.; Wright, I.G.; Hanrahan, R.J., Jr. High-Temperature Oxidation and Corrosion of Metals. In Materials Science and Technology: A Comprehensive Treatment Materials Science and Technology: A Comprehensive Treatment: Corrosion and Environmental Degradation, Volumes I+II, 1; Cahn, R.W., Haasen, P., Kramer, E.J., Eds.; Wiley-VCH Verlag GmbH \& Co., KGaA: Weinheim, Germany, 2008; pp. 229-325.

36. Naumenko, D.; Gleeson, B.; Wessel, E.; Singheiser, L.; Quadakkers, W.J. Correlation between the microstructure, growth mechanism, and growth kinetics of alumina scales on a FeCrAlY alloy. Metall. Mater. Trans. A 2007, 38, 2974-2983. [CrossRef]

37. Burtin, P.; Brunelle, J.P.; Pijolat, M.; Soustelle, M. Influence of surface area and additives on the thermal stability of transition alumina catalyst supports. I: Kinetic data. Appl. Catal. 1987, 34, 225-238. [CrossRef]

38. Lelait, L.; Alpérine, S.; Mévrel, R. Alumina scale growth at zirconia-MCrAlY interface: A microstructural study. J. Mater. Sci. 1992, 27, 5-12. [CrossRef]

39. Li, M.; Zhang, Z.; Sun, X.; Li, J.; Yin, F.; Hu, W.; Guan, H.; Hu, Z. Oxidation behavior of sputter-deposited NiCrAlY coating. Surf. Coat. Technol. 2003, 165, 241-247. [CrossRef]

40. Paladino, A.E.; Kingery, W.D. Aluminum ion diffusion in aluminum oxide. J. Chem. Phys. 1962, $37,957$. [CrossRef]

41. Ramanarayanan, T.A.; Raghavan, M.; Petkovic-Luton, R. Metallic yttrium additions to high temperature alloys: Influence on $\mathrm{Al}_{2} \mathrm{O}_{3}$ scale properties. Oxid. Met. 1984, 22, 83-100. [CrossRef]

42. Ogawa, K.; Ito, K.; Shoji, T.; Seo, D.W.; Tezuka, H.; Kato, H. Effects of Ce and Si additions to CoNiCrAlY bond coat materials on oxidation behavior and crack propagation of thermal barrier coatings. J. Therm. Spray Technol. 2006, 15, 640-651. [CrossRef]

(C) 2018 by the authors. Licensee MDPI, Basel, Switzerland. This article is an open access article distributed under the terms and conditions of the Creative Commons Attribution (CC BY) license (http:/ / creativecommons.org/licenses/by/4.0/). 